\title{
Combined method of opencast and underground mining of valuable ore
}

\author{
Niyaz Valiev ${ }^{1 *}$, Vyacheslav Berkovich ${ }^{1}$, Vladimir Propp ${ }^{1}$, and Konstantin Kokarev ${ }^{1}$ \\ ${ }^{1}$ Federal State Budgetary Educational Institution of Higher Education "Ural State Mining \\ University" Yekaterinburg, Russia.
}

\begin{abstract}
The efficiency of the combined opencast and underground mining of deposits directly depends on the overburden amount within the open pit boundaries. The amount of overburden to be removed, in its turn, is determined by the angles of the open pit slopes. At the same time, the influence of the open pit slope angle on the amount of the rock mass within the open-pit contours increases in an arithmetic progression with the mining depth. This fact confirms the direct relationship between the open pit slope angle and the efficiency of the mining operations from both an economic and ecological points of view. The article considers the technology for mining steeply inclined deposits of valuable ores by means of underground chambers mined out in advance with consolidating stowing to support unworked sides of an open pit called "well". The chambers which can be not only vertical but also inclined at an angle of $60-80^{\circ}$ serve to create an artificial fence (a ring concrete support). The work of the fence supporting the open pit side is markedly different from that of retaining walls of any type since the consolidating stowing mixture used to create the fence provides an ideal contact of the concrete wall with the enclosing rocks, thus making it impossible for an artificial fence to overturn. The proposed combined mining technology is expected to reduce considerably the number of the overburden operations, to minimize the damage caused by mining operations to the environment, and to increase the intensity of mine workings.
\end{abstract}

\section{Introduction}

In our country and abroad mining practice makes an increasingly wider use of combined (simultaneous or consecutive) opencast and underground mining of one and the same mineral deposit and therefore ensures its complete extraction and protection of subsoil with lower costs of mining mineral raw materials with simultaneous decrease of harmful influence on the environment. The combined mining method aims at increasing the efficiency of both opencast

*Corresponding author: science@ursmu.ru 
and underground mining operations by means of the combined use of their most advantageous technological characteristics.

The efficiency of opencast mining is known to depend directly on the overburden amount within the open pit boundaries. The amount of overburden to be removed, in its turn, is determined by the angles of the open pit slopes. At the same time, the influence of the open pit slope angle on the amount of the rock mass within the open-pit contours increases in an arithmetic progression with the mining depth. Thus, there is a direct relationship between the open pit slope angle and the efficiency of the mining operations from both economic and ecological points of view. The open pit slope angle is the result of stripping and mining methods used in open-pit workings. In general, it is reflected in two values of the open pit slope angle: constructive and stable ones. Each of these angles must be as high as possible for a given deposit. However, it is required that the constructive value angle should not exceed the stable value one. Vertical open pit slopes are certain to be an ideal condition which can be created due to the combined method of mining. Using the advantages of the underground mining, it is possible to lay the foundation for surface mining of deposits with steep open pit slopes.

\section{Theoretical propositions}

There is a tendency for the combined development of steep ore deposits to use a technology with unworked open slopes equal to 70-90 ${ }^{\circ}$. Academician V.V. Rzhevskiy called this technology "unbenched" mining or "well" mining [1]. For the application of this mining method it is important to maintain the stability of steep open pit slopes. In order to mine the deposits with the slope angles ranging from steep to vertical, it is necessary to solve two major problems. The first one is "how to extract a useful mineral and what means to use to bring it to the surface"; and the second one is "how to maintain stability of the open pit slopes at the angles close to vertical".

The article describes a method which makes use of underground chambers mined out in advance with consolidating stowing to support unworked slopes of an open pit called "a well". They can be not only vertical but also inclined at an angle of 60-800 (the angles are determined by the stability condition of the enclosing rocks [2]). The essence of the method boils down to the following (Fig. 1).

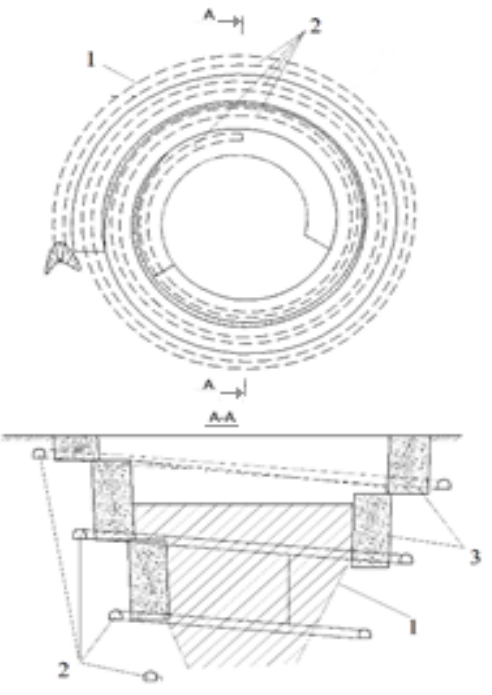

Fig. 1. Unbenched mining of the ore body:

1 - working zone contours; 2 - spiral stoping; 3 - ring support 
The upper part of the deposit is worked out to the optimum depth by means of a traditional technology of the opencast mining. At the same time, an underground open pit is prepared by means of an unbenched mining technology to clean up the pit reserves of ore. For this purpose, outside the contours of the working zone of a deposit, a spiral stoping with an inclination allowing the use of self-propelled equipment is sunk downwards. In parallel with the spiral stoping along the contours of the working zone of the deposit, the worked-out space is formed for the construction of the advance support (a well) by means of sequential working of the primary and secondary chambers. For this reason, the spiral stoping is used to drive drilling and haulage workings to drill and blast chamber reserves. The blasted rock is transported by the self-propelled equipment through the spiral working to the surface. After the chambers are worked out and cleaned up, they are stowed with consolidating mixture. Secondary chambers are worked out after the consolidating stowing develops its normative strength (Fig. 2).

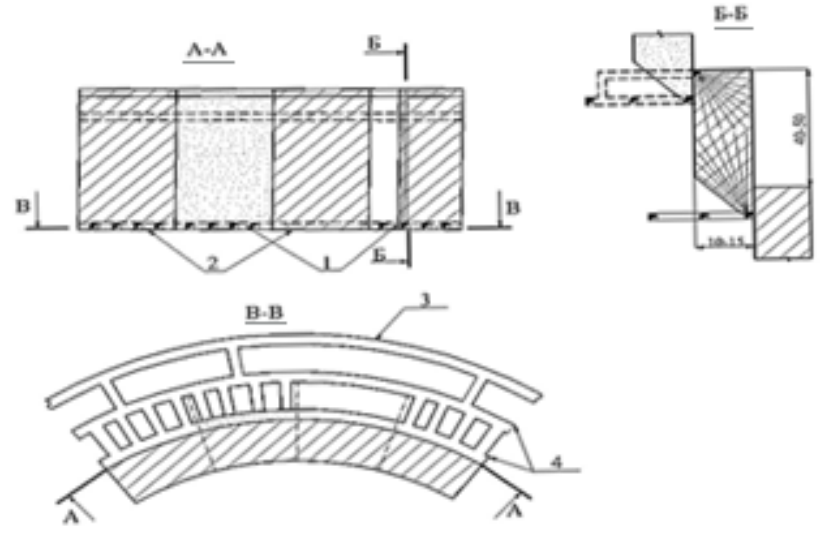

Fig. 2. Technology for construction of the ring support: 1-primary chambers; 2-secondary chambers; 3-spiral ramp; 4-drilling and haulage workings

Ventilation of the preparatory-development workings is carried out by means of the plenum system with the air flowing through the ventilation holes drilled from the surface. After the construction of the first turn of the ring support, the reserves inside the well are worked out by means of an opencast mining directed from the center to the periphery (to the "well" support). Along with these works, the "well" supports are built up by excavating a trench from the surface to the depth of the first turn of the ring support to transport the bulk of the ore reserves by means of the underground method. The ore reserves under the trench are worked out for last. In this case, the ore is also hauled to the surface along the spiral working. Thus, it is possible to work out a steep ore body limited in plan more intensively thanks to a continuous excavation of ore reserves in the central and peripheral parts.

For the construction of a ring support along with the chamber-level mining method described above, it is possible to use dipping flat-back cut-and-fill system. The choice of the mining method depends on the properties of the enclosing rocks and their stability. The combined method of ore mining makes it possible to reduce significantly the overburden amount and the area of the mined-out land.

It should be noted that the work of the artificial fence (concrete ring support) supporting the open pit side is markedly different from that of retaining walls of any type since the consolidating stowing mixture used to create the fence provides an ideal contact of the concrete wall with the enclosing rocks, thus making it impossible for an artificial fence to overturn.

To give a more accurate assessment of the effect of the artificial fence surcharge weight on the stability of the open pit slopes, a series of calculations was made according to V.G. Zoteev [3]. The calculations were made for the open pit sides having slope angles of $50^{\circ}$ and $70^{\circ}$. The 
open pit depth in both cases was $200 \mathrm{~m}$. The angle of internal friction of the massif and adhesion in it were assumed to be equal to $26^{\circ}$ and $0.6 \mathrm{MPa}$ respectively while the massif density amounted to $2.75 \mathrm{t} / \mathrm{m} 3$. In the calculations the height of the artificial fence varied from 0 to $200 \mathrm{~m}$ in increments of $20 \mathrm{~m}$. The thickness (normal density) of the concrete wall was assumed to be the same throughout the height of the side. At the same time, the stability coefficient was calculated for each height of the fence with different thickness set equal to 10 , 20 and $30 \mathrm{~m}$. The results of the calculations in the form of the graphical representation of the dependence of the stability coefficient on the height and thickness of the artificial fence are shown in Fig. 3.

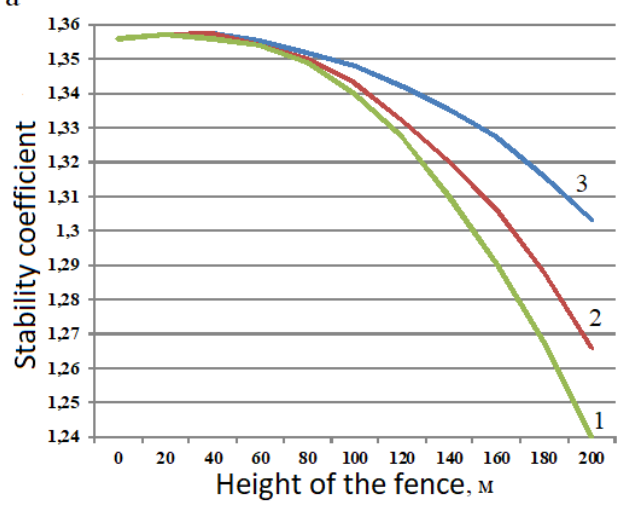

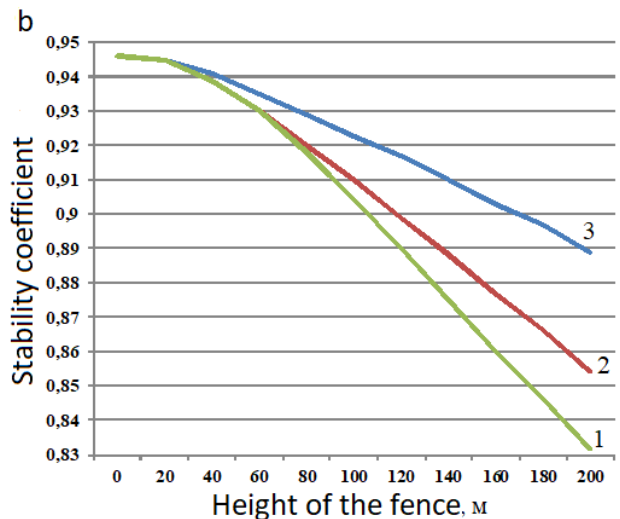

Fig.3. Change in the stability coefficient of the open pit sides:

a) with a slope angle of $50^{\circ}$; b) with a slope angle of $70^{\circ}$;

$1,2,3$ - the fence thickness set equal to $10 \mathrm{~m}, 20 \mathrm{~m}$ and $30 \mathrm{~m}$ respectively

With the increase in the height and thickness of the artificial fence, the stability coefficient decreases according to the non-linear law. The convex character of the graphs and the divergence of the branches corresponding to different thicknesses of the fence indicate that the intensity of the decrease in stability grows with the increase in height and thickness of the fence. With the increase in the angle of inclination of the open pit side, the decrease in the stability coefficient during the construction of the fence throughout the height of the exposure can reach $12 \%$ or more.

The artificial fence to be erected has height limitations determined by the strength of the stowing, the angle of the inclination, and the thickness of the fence to be constructed, as well as the rate and the ratio of the initial stresses (the higher the ratio between horizontal and vertical stresses, the greater the ratio between the width of the fence and its height). In order to overcome the limitations, in principle, an artificial fence should be erected in the form of several isolated benches (Fig. 4). Each of the benches can have its slope and thickness determined in accordance with the engineering and geological characteristics of the rock massif. Since a harder and stronger rock massif will support each part of the fence, the stress concentration zones will be separated in space. In addition, the proposed technology makes it possible to increase the scope of work aimed at the construction of an artificial fence, since the fence on each bench can be erected independently of the other ones. 


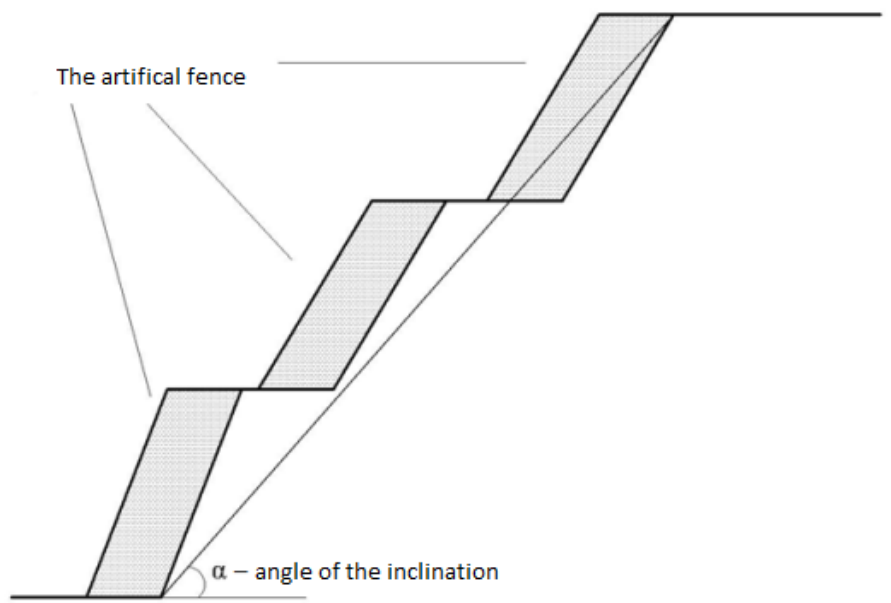

Fig. 4. Structure of an artificial fence

\section{Results and discussion}

The basic concepts of the proposed technology were used to plan the development of Shemurskoye and Novo-Shemurskoye deposits of copper-sulphide ores on the eastern slope of the Northern Ural. Located at the distance of $2 \div 5 \mathrm{~km}$ from the nature reserve "Denezhkin Kamen", they have a grim prospect to be mined in a traditional way in view of the great ecological danger. The proposed mining technology with a minimum damage to the earth interior makes it very promising.

In the northern and central parts the ore zone of Shemurskoye deposit has thickness up to $200 \mathrm{~m}$. The angle of the ore zone dip reaches $50^{\circ}$. The central part of the deposit is exposed to the surface. The harmful impurities in the ores are lead, arsenic, antimony and fluorine. The balance reserves of $\mathrm{C} 1+\mathrm{C} 2$ category copper ore amount to5.1 million tons.

The plan of Shemurskoye deposit development is carried out in a traditional way. The open pit is $120 \mathrm{~m}$ deep, $630 \mathrm{~m}$ along the strike, and $370 \mathrm{~m}$ wide. The rock mass output is 10720 thousand $\mathrm{m} 3$, including overburden accounting for 8920 thousand $\mathrm{m} 3$. The average stripping ratio is $1.7 \mathrm{~m} 3 / \mathrm{t}$. The open pit mine production is 800 thousand tons of ore per year. The mine life is 8.5 years.

When various parameters of the support (artificial concrete fence) were compared, the ring support with an upper mark of $750 \mathrm{~m}$, an outer diameter of $100 \mathrm{~m}$ at the top, an external diameter of $50 \mathrm{~m}$ at the bottom $(630 \mathrm{~m})$, a height of $120 \mathrm{~m}$, and a thickness of $14 \mathrm{~m}$ appeared to be the most optimal (Fig. 5).

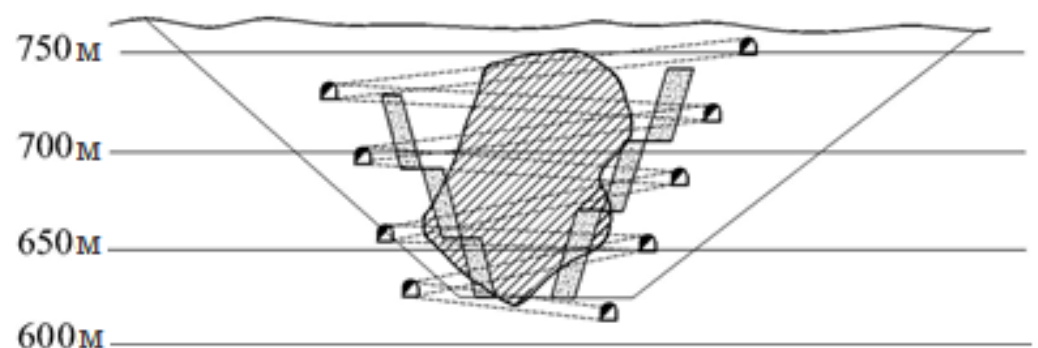

Fig. 5. The alternative method of mining of Shemurskoye deposit with steep unworked sides 
The technology of the ring support construction makes it possible to work simultaneously with seven chambers. Before the beginning of the opencast mining, at least two turns of the ring support must be ready inside the well. It means that 14 chambers must be worked out by the underground method of mining and that it will take 3 years to do this.

Novo-Shemurskoye deposit is expected to be developed in a similar way. An alternative to the project is supposed to be a combined mining method. The central part of the deposit, which is $240 \mathrm{~m}$ above the horizon, is worked out by an open pit with the depth of $190 \mathrm{~m}$. The rock mass output will be 31.0 million $\mathrm{m}^{3}$. The south-eastern section of the deposit below the mark of $200 \mathrm{~m}$ is mined by means of a new unbenched technology (Fig. 6). Moreover, the time schedule of the preparation, construction, and operation of the mine makes it possible to construct the underground "well" up to the mark of $50 \mathrm{~m}$ during the time of the open pit mining (up to the abslute mark of $200 \mathrm{~m}$ ). The parameters of the "well" will be approximately the same as those at the Shemurskoye deposit.

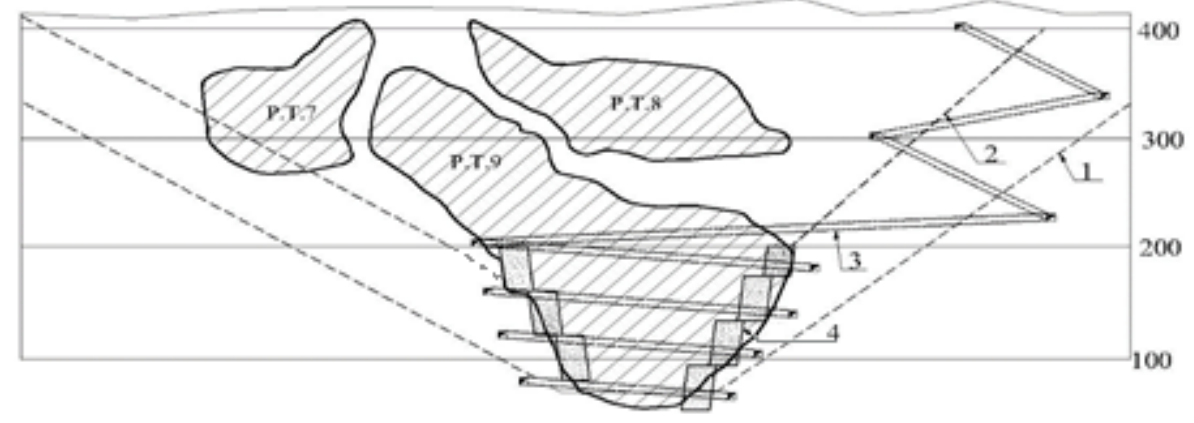

Fig. 6. Combined method of Novo-Shemurskoye deposit mining: 1 - project-oriented open pit contours; 2 -new open pit contours; 3 - inclined ramp; 4 - ring support.

The costs associated with the construction of the ring concrete support include the cost of driving an inclined ramp and underground mining of the chambers with consolidating stowing. The main technical and economic indicators associated with the mining of Shemurskoye and NovoShemurskoye deposits by means of the unbenched mining technology in comparison with the project-oriented traditional mining method are given in the Table. As can be seen from the table, the rock mass output is 5-8 times less when deposits are mined by means of a new technology than when they are extracted in a traditional way. This happens due to the reduction of the overburden operations, which, in its turn, minimizes the damage to the land, the cost of mining operations and solves many environmental problems of mining.

Table 1. Comparison of technical and economic indicators associated with the development of Shemurskoye and Novo-Shemurskoye deposits

\begin{tabular}{|l|l|l|l|l|}
\hline \multirow{2}{*}{ Indicators } & \multicolumn{4}{|c|}{ Deposit } \\
\cline { 2 - 5 } & \multicolumn{2}{|c|}{ Novo-Shemurskoye } & \multicolumn{2}{c|}{ Shemurskoye } \\
\cline { 2 - 5 } & \multicolumn{1}{|c|}{ Alternative } & \multicolumn{2}{c|}{ Alternative } \\
\cline { 2 - 5 } & $\begin{array}{l}\text { project- } \\
\text { oriented }\end{array}$ & proposed & $\begin{array}{l}\text { project- } \\
\text { oriented }\end{array}$ & proposed \\
\hline $\begin{array}{l}\text { Total rock mass output, million } \mathrm{m}^{3} \\
\text { including }\end{array}$ & 247.0 & 31.0 & 10.7 & 2.1 \\
\hline overburden & 238.7 & 27.6 & 8.9 & - \\
\hline ore & 8.3 & 5.5 & 1.8 & 2.0 \\
\hline Total cost of 1 $\mathrm{m}^{3}$ of rock mass, rub & 1026.6 & 254.5 & 193.0 & 180.0 \\
\hline $\begin{array}{l}\text { Total costs of a deposit mining, } \\
\text { million rubles }\end{array}$ & 8521.0 & 1403.0 & 347.5 & 360.0 \\
\hline
\end{tabular}




\section{Conclusion}

1. The conducted researches and feasibility study of the economic efficiency evaluation of the proposed combined opencast-underground method of mining have shown that the proposed technology makes it possible to reduce the costs of mining, to minimize the damage caused by mining to the environment, and to increase the intensity of the deposit development.

2. The development and justification of the proposed technology will require a new approach to the opencast and underground mining operations, the use of new constructive solutions, as well as an in-depth study of the mechanism of interaction of the system open pit side-ring support from the geomechanical point of view.

\section{References}

1. Rzhevskiy V. V. Problems of the mining industry and the complex of mining sciences.

V. V. Rzhevskiy. Scientific publishing house:Moscow Mining Institute. 240 p. (1991).

2. Inventor's certificate 1745931 Russian Federation. Method of mining mineral deposits / V.M. Berkovich [and others]. No. 4827141/03; claimed 21.05.90; published. 07.07.92, Bul. 25.

3. Zoteev V.G., Zoteev O.V., Tarasov E.B. The method of slip surfaces construction for the calculation of stability of enclosing dams accumulating liquid industrial waste. "Izvestiya. Vuzov". Mining magazine. 3. P. 33-38. (2005). 